\title{
Interplay Between Cognitive and Bowel/Bladder Function in Multiple Sclerosis
}

\author{
Antonio Carotenuto, Teresa Costabile, Marcello Moccia, Fabrizia Falco, Maria Petracca, Barbara Satelliti, Cinzia Valeria Russo, \\ Francesco Saccà, Roberta Lanzillo, Vincenzo Brescia Morra \\ Department of Neurosciences, Reproductive and Odontostomatological Sciences, 'Federico II’ University, Naples, Italy
}

Purpose: The aim of this study was to evaluate the prevalence of bowel/bladder dysfunction in multiple sclerosis (MS) and its associations with cognitive impairment.

Methods: We prospectively enrolled 150 MS patients. Patients were administered the Symbol Digit Modality Test (SDMT), the Neurogenic Bowel Dysfunction Score (NBDS), and the Actionable Bladder Symptom Screening Tool (ABSST). The associations between bowel/bladder dysfunction and cognitive function were assessed through hierarchical regression models using the SDMT and clinicodemographic features as independent variables and NBDS and ABSST scores as dependent variables.

Results: The prevalence of bowel/bladder deficits was $44.7 \%$, with 26 patients (17.3\%) suffering from bowel deficits and 60 patients (40\%) from bladder deficits. The total NBDS and ABSST scores were correlated with the SDMT $(\beta=-0.10, \mathrm{P}<0.001$ and $\beta=-0.03, P=0.04$, respectively) after correction for demographic features and physical disability.

Conclusions: Bowel/bladder disorders are common in MS and are associated with both physical and cognitive disability burdens. As SDMT is embedded into routine clinical assessments, a lower score may warrant investigating bowel/bladder dysfunction due to the strong interplay of these factors.

Keywords: Bowel; Bladder; Cognition; Disability; Patient-Reported Outcome

\footnotetext{
- Research Ethics: The study was approved by the Institutional Review Board of the University of Naples 'Federico II' (143/19) and all investigators adhered to the tenets of the Declaration of Helsinki. Written informed consents were obtained from all subjects enrolled in the study.

- Conflict of Interest: Antonio Carotenuto received research grants from Almirall and the ECTRIMS-MAGNIMS Society, and honoraria form Novartis, Merck, and Biogen. Teresa Costabile received honoraria from Roche and Novartis. Antonio Carotenuto received research grants from Almirall, and honoraria from Novartis, Merck, and Biogen. Marcello Moccia has received research grants from ECTRIMS-MAGNIMS, the UK MS Society, and Merck; honoraria from Biogen, Merck, Novartis, and Roche; and consulting fees from Veterans Evaluation Services. Roberta Lanzillo received personal compensations for speaking or consultancy from Biogen, Teva, Genzyme, Merck, Novartis, and Almirall. Maria Petracca received a travel grant from Novartis. Vincenzo Brescia Morra received personal compensations for speaking or consultancy from Biogen, Teva, Genzyme, Merck, Novartis, and Almirall. Barbara Satelliti, Fabrizia Falco, and Valeria Russo Cinzia declare no potential conflicts of interest with respect to the research, authorship and/or publication of this paper. Francesco Saccà has received speaking honoraria from Biogen, Mylan, Novartis, Roche, Sanofi, and Teva, and has served on advisory boards for Almirall, Argenx, Avexis, Biogen, Forward Pharma, Merck, Novartis, Pomona, Roche, and Sanofi.
}

Corresponding author: Carotenuto Antonio (iD https://orcid.org/0000-0002-1574-9693 Department of Neurosciences, Reproductive and Odontostomatological Sciences, 'Federico II’ University, Via Pansini 5, 80131, Naples, Italy Email: carotenuto.antonio87@gmail.com Submitted: September 21, 2020 / Accepted after revision: November 29, 2020
This is an Open Access article distributed under the terms of the Creative Commons Attribution Non-Commercial License (https://creativecommons.org/licenses/by-nc/4.0/) which permits unrestricted non-commercial use, distribution, and reproduction in any medium, provided the original work is properly cited. 


\section{INTRODUCTION}

Multiple sclerosis (MS) is a disabling immune-mediated disorder of the central nervous system that mostly affects young adults. MS-related physical disability has a negative impact on quality of life and harshly affects patients' life both socially and economically [1,2]. MS-related symptoms encompass a wide variety of deficits, including, but not limited to, visual disturbances, motor weakness, sensory changes, and ataxia. Bowel/ bladder deficits, such as retention or incontinence, are also detected in about $52 \%-97 \%$ of MS patients and are conventionally thought to be associated with spinal cord pathology [3,4]. Although these symptoms are extremely distressing and impact patients' social and work life [5], patients are usually reluctant to discuss them due to the embarrassing nature of the matter [6]. In addition, clinicians do not always ask about bowel and bladder dysfunction because of the limited timeframe for the clinical assessment, increasing the underestimation of bowel/ bladder disorders in MS patients. Therefore, there is a need for clinical clues and screening tools for bowel/bladder dysfunction in patients with MS. This is especially true when considering that when correctly diagnosed, bowel/bladder dysfunction may benefit from a variety of symptomatic treatments, such as anticholinergic drugs, desmopressin, intermittent self-catheterization, cannabinoids, detrusor injections of botulinum neurotoxin type A, and surgical management [7].

Cognitive function is thought to play a key role in controlling bowel/bladder function in healthy subjects [8]. Patients affected by impaired cognitive function caused by neurological conditions such as vascular dementia and Parkinson disease also display issues in controlling bowel and bladder function $[9,10]$. The association between cognitive performance and bowel/ bladder control may depend upon the strong overlap of brain structures activated by both functions, namely, the prefrontal cortex, the thalamus, the cerebellum, and the brainstem $[11,12]$. As cognitive impairment can be detected in up to $75 \%$ of MS patients [13,14], mostly affecting processing speed, attention, executive functioning, and working memory $[13,15]$, it is reasonable to hypothesize that cognitive impairment may be a red flag for bowel/bladder dysfunction in MS, as for other neurological conditions.

Thus, with this study, we aimed (1) to estimate the prevalence of both bowel and bladder dysfunction in MS patients, and (2) to evaluate their associations with cognitive function.

\section{MATERIALS AND METHODS}

\section{Subject Enrolment}

In this cross-sectional study, patients diagnosed with MS according to the $2017 \mathrm{McD}$ onald's criteria [16] were prospectively and consecutively enrolled at the MS center of "Federico II" University of Naples (Italy) between September and December 2019. The inclusion criteria were: (1) age between 18 and 65 years old, and (2) an Expanded Disability Status Scale (EDSS) $\leq 7.5$. We excluded patients with (1) any disorder other than MS leading to bowel/bladder dysfunction (i.e., major malformations, major cardiovascular risk factors, other major psychiatric conditions); (2) patients receiving concomitant treatments that may lead to bowel/bladder dysfunction (i.e., antidepressants, verapamil, or beta-blockers); (3) clinical relapse in the 6 months preceding the screening of the patient's clinical history. For each patient, we collected clinical and demographic data, including an assessment of physical disability through the EDSS and the bowel/bladder subscale, educational level, treatment status, and disease course. In order to disentangle real bowel/ bladder incontinence from incontinence related to limited mobility, we divided patients according to the extent of physical disability into fully ambulatory patients (EDSS $\leq 4.0$ ) and patients with ambulation restrictions. Finally, as a global assessment of patients' cognition, we administered the Symbol Digit Modality Test (SDMT), since it is widely accepted as a screening tool for cognitive impairment in MS [17,18].

The study was approved by the Institutional Review Board of the "Federico II" University of Naples and all investigators adhered to the tenets of the Declaration of Helsinki. Written informed consent forms were obtained from all subjects enrolled in the study.

\section{Neurogenic Bowel Dysfunction Score}

Each patient filled in the self-administered Neurogenic Bowel Dysfunction Score (NBDS) questionnaire to assess bowel function [19]. The NBDS is a 10-item multiple-choice questionnaire assessing the frequency of bowel movements, headache, perspiration, or discomfort during defecation; use of medication for constipation or fecal incontinence; time spent on defecation; frequency of digital stimulation or evacuation; frequency of fecal incontinence; flatus; and perianal skin problems. A score is assigned for the selected answer for each item, and the total score can be calculated by summing the scores for each answer. The total score can be converted to a categorical assessment of 
very low, low, moderate, or severe neurogenic bowel dysfunction. The NBDS has been validated in MS [20] and is widely used as a primary outcome in trials assessing the impact of treatment on bowel function [21]. Patients were classified as having bowel dysfunction if their total NBDS score was $\geq 10$. In addition, each patient also completed a 0 to 10 numerical rating scale (NRS) for bowel function satisfaction, with 10 representing the maximal satisfactory level.

\section{Actionable Bladder Symptom Screening Tool}

The Actionable Bladder Symptom Screening Tool (ABSST) was administered to each patient. As with the NBDS, the ABSST is also a self-administered questionnaire. It is a short 8-item questionnaire specifically designed to assess bladder function in MS patients [22,23]. Each item is scored on a scale from 0 to $1(0=$ none of the time, $0=$ some of the time, $1=$ most of the time, and $1=$ all of the time) and the scores reported for each item are summed up to the total score. A total score equal or higher than 3 is interpreted as a warning for bladder dysfunction $[22,23]$.

\section{Statistical Analyses}

Statistical analyses were performed using Stata 13 (StataCorp LP, College Station, TX, USA). Demographic and clinical features are presented as means, medians, or proportions, as appropriate. Between-group comparisons were performed using the Student t-test or analysis of variance as appropriate. Pairwise correlations were assessed through the Pearson correlation test. In order to evaluate the additional impact of cognitive function on bowel and bladder dysfunction over and above demographic features and physical disability status, we applied 3 separate hierarchical linear regression procedures, using alternatively NRS for bowel function or NBDS or ABSST scores as dependent variables. In the first step, demographic variables (age, sex, and education) were entered into the models. The second step added the illness-related variables (physical disability status, disease course, disease duration, annualized relapse rate), and the third step added the SDMT score. The Nagelkerke $\mathrm{R}^{2}$ for each model is reported. The normality of the distribution of variables and residuals were evaluated with the Shapiro-Wilk test and graphical approaches. The results were considered statistically significant at $\mathrm{P}<0.05$.

\section{RESULTS}

We enrolled 150 MS patients (91 females and 59 males) with a
Table 1. Demographic and clinical data of the sample $(n=150)$

\begin{tabular}{|c|c|}
\hline Characteristic & Value \\
\hline \multicolumn{2}{|l|}{ Sex } \\
\hline Male & $59(39.3)$ \\
\hline Female & $91(60.7)$ \\
\hline Age $(y r)$, mean \pm SD (range) & $43.3 \pm 11.5(18-65)$ \\
\hline Education (yr) & $13(0-18)$ \\
\hline EDSS & $3.5(0-7.5)$ \\
\hline \multicolumn{2}{|l|}{ Ambulation status } \\
\hline Fully ambulatory & $101(67)$ \\
\hline Ambulation restriction & $49(33)$ \\
\hline Disease duration (yr) & $10.5(0-40)$ \\
\hline Annualized relapse rate & $0.37(0-2)$ \\
\hline \multicolumn{2}{|l|}{ Disease course } \\
\hline Relapsing-remitting & $108(72)$ \\
\hline Secondary-progressive & $36(24)$ \\
\hline Primary-progressive & $4(6)$ \\
\hline \multicolumn{2}{|l|}{ Disease-modifying treatment } \\
\hline No treatment & $1(0.7)$ \\
\hline Interferon beta & $21(14)$ \\
\hline Glatiramer acetate & $5(3.3)$ \\
\hline Dimethyl fumarate & $13(8.7)$ \\
\hline Fingolimod & $15(10)$ \\
\hline Cladribine & $1(0.7)$ \\
\hline Natalizumab & $38(25.3)$ \\
\hline Teriflunomide & $6(4)$ \\
\hline Alemtuzumab & $19(12.7)$ \\
\hline Ocrelizumab & $22(14.7)$ \\
\hline Rituximab & $7(4.7)$ \\
\hline Siponimod & $2(1.2)$ \\
\hline
\end{tabular}

Values are presented as number (\%) or median (range) unless otherwise indicated.

SD, standard deviation; EDSS, Expanded Disability Status Scale.

mean age of $43.3 \pm 11.5$ years and mean disease duration of $11.8 \pm 7.6$ years. Patients' demographic and clinical data are summarized in Table 1. All patients had SDMT, NBDS, and ABSST data. The scores for each test are summarized in Table 2. The overall prevalence of bowel or bladder deficits was $44.7 \%$, with 26 patients out of 150 (17.33\%) suffering from bowel deficits, and 60 out of 150 patients (40\%) from bladder deficits. Nineteen of the 150 MS patients (12.7\%) presented both bowel and bladder dysfunction. Patients with bowel/bladder deficits were not different in terms of the sex distribution compared 
Table 2. Results from bowel/bladder questionnaires and cognitive function

\begin{tabular}{lcc}
\hline Test & Value & Reference score \\
\hline Neurogenic bowel dysfunction (numerical rating scale) & $7.24 \pm 2.55$ & $0-10$ \\
Neurogenic bowel dysfunction (total score) & $4.54 \pm 6.38$ & $0-47$ \\
Neurogenic bowel dysfunction, disability level & & $0-6$ \\
Very low & $110(73.3)$ & $14(9.3)$ \\
Low & $10(6.7)$ & $7-9$ \\
Moderate & $16(10.7)$ & $10-13$ \\
Severe & $2.70 \pm 2.83$ & $14-47$ \\
Actionable Bladder Symptom Screening Tool & $40.42 \pm 18.51$ & $0-8$ \\
SDMT & & $0-110$ \\
\hline
\end{tabular}

Values are presented as mean \pm standard deviation or number (\%).

SDMT, Symbol Digit Modality Test.

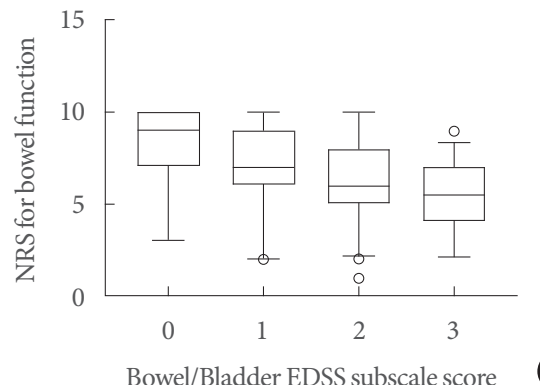

Bowel/Bladder EDSS subscale score

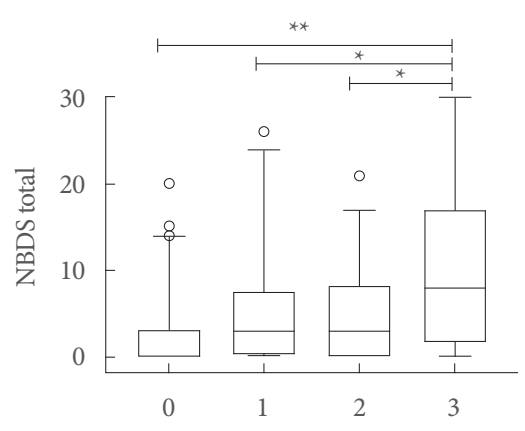

A Bowel/Bladder EDSS subscale score

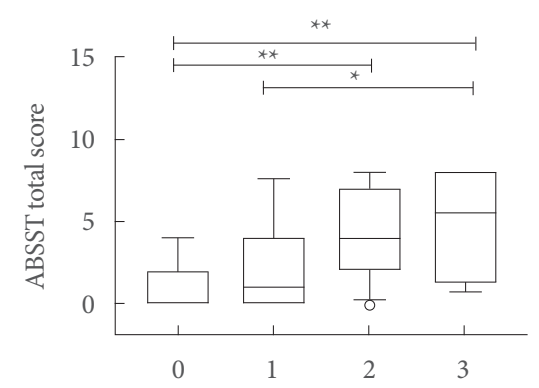

0

Fig. 1. Bowel/bladder dysfunction as assessed through the EDSS subscales, NBDS, and ABSST total scores. Box-and-whisker plot displays the median and 5th, 25th, 75th, and 95th percentiles for numerical rating scale (NRS) for bowel function (A), total NBDS scores (B), and ABSST total score (C). EDSS, expanded Disability Status Scale; NBDS, Neurogenic Bowel Dysfunction Score; ABSST, Actionable Bladder Symptom Screening Tool. ${ }^{\star} \mathrm{P}<0.05,{ }^{\star *} \mathrm{P}<0.001$ after Bonferroni correction.

with MS patients without deficits, but they were older (46.7 \pm 10.7 years vs. $40.6 \pm 11.4$ years, $\mathrm{P}=0.001)$, had higher EDSS scores ( $4.54 \pm 1.52$ vs. $3.17 \pm 1.83, \mathrm{P}<0.001)$, were more likely to have a progressive course of the disease (58.2\% vs. $41.8 \%, \mathrm{P}=$ $0.002)$, and had lower SDMT scores (34.6 \pm 19.3 vs. $45.1 \pm 16.5$, $\mathrm{P}<0.001)$.

The NRS for bowel function did not differ between male and female patients and between patients with a relapsing or progressive disease course, whilst it was higher in fully ambulatory patients than in patients with ambulation restriction $(7.72 \pm 2.31$ vs. $6.10 \pm 2.73, \mathrm{P}<0.001)$. The NRS for bowel function correlated with age $(r=-0.25, P=0.004)$, disease duration $(r=-0.29$, $\mathrm{P}<0.001)$, EDSS $(\mathrm{r}=-0.43, \mathrm{P}<0.001)$, and SDMT $(\mathrm{r}=0.23$, $\mathrm{P}=0.003$ ). The NRS for bowel function did not differ according to the bowel/bladder EDSS subscale score (Fig. 1A).

The total NBDS did not differ between male and female pa- tients and between patients with a relapsing or progressive disease course, whilst it was lower in fully ambulatory patients than in patients with ambulation restriction $(3.33 \pm 5.35$ vs. $7.04 \pm 7.55, \mathrm{P}<0.001)$. The total NBDS was correlated with age $(\mathrm{r}=0.23, \mathrm{P}=0.005)$, disease duration $(\mathrm{r}=0.16, \mathrm{P}=0.04)$, EDSS $(\mathrm{r}=0.39, \mathrm{P}<0.001)$, and SDMT $(\mathrm{r}=-0.43, \mathrm{P}<0.001)$. The total NBDS also differed according to the bowel/bladder EDSS subscale score $(\mathrm{P}<0.001$, Fig. $1 \mathrm{~B})$.

The ABSST total score did not differ according to sex and disease course, whilst it was lower in fully ambulatory patients than in patients with ambulation restriction $(2.06 \pm 2.54$ vs. $4.18 \pm 2.93, \mathrm{P}<0.001)$. The ABSST total score was correlated with age $(\mathrm{r}=0.31, \mathrm{P}<0.001)$, EDSS $(\mathrm{r}=0.45, \mathrm{P}<0.001)$, and SDMT $(r=-0.36, P<0.001)$, and it differed according to the bowel/bladder EDSS subscale score ( $\mathrm{P}=0.04$, Fig. $1 \mathrm{C})$. The ABSST total score was correlated with both the total NBDS 
Table 3. Prediction of Neurogenic Bowel Dysfunction Score and Actionable Bladder Symptom Screening Tool score

\begin{tabular}{|c|c|c|c|c|c|c|c|}
\hline Score & $\begin{array}{c}\text { Nagelkerke } \\
\mathrm{R}^{2}\end{array}$ & $\begin{array}{c}\mathrm{R}^{2} \\
\text { change }\end{array}$ & $\begin{array}{l}\text { P-value for } \\
\text { change }\end{array}$ & Coefficient & $95 \% \mathrm{CI}$ & $\begin{array}{c}\text { Beta } \\
\text { coefficient }\end{array}$ & P-value \\
\hline \multicolumn{8}{|l|}{ Neurogenic Bowel Dysfunction Score } \\
\hline First step & 0.11 & - & - & & & & \\
\hline Second step & 0.17 & 0.06 & 0.09 & & & & \\
\hline Third step & 0.21 & 0.04 & $0.01^{*}$ & & & & \\
\hline \multicolumn{8}{|l|}{ Variables (third step) } \\
\hline Female vs. male & & & & 0.47 & -1.55 to 2.50 & 0.04 & 0.65 \\
\hline Age & & & & -0.03 & -0.14 to 0.08 & -0.06 & 0.58 \\
\hline Education (yr) & & & & -0.16 & -0.45 to 0.14 & -0.10 & 0.29 \\
\hline Patients with ambulatory restriction vs. fully ambulatory & & & & 0.21 & -2.66 to 3.08 & 0.02 & 0.88 \\
\hline Secondary progressive vs. relapsing-remitting & & & & 1.99 & -1.12 to 5.09 & 0.13 & 0.21 \\
\hline Primary-progressive vs. relapsing-remitting & & & & 1.40 & -4.16 to 6.96 & 0.04 & 0.62 \\
\hline Disease duration & & & & 0.07 & -0.08 to 0.22 & 0.08 & 0.36 \\
\hline Annualized relapse rate & & & & 0.07 & -2.51 to 2.65 & 0.00 & 0.96 \\
\hline SDMT score & & & & -0.10 & -0.18 to -0.02 & -0.30 & $0.01^{*}$ \\
\hline \multicolumn{8}{|l|}{ Actionable Bladder Symptom Screening Tool score } \\
\hline First step & 0.09 & - & - & & & & \\
\hline Second step & 0.16 & 0.06 & 0.06 & & & & \\
\hline Third step & 0.18 & 0.03 & $0.03^{*}$ & & & & \\
\hline \multicolumn{8}{|l|}{ Variables (third step) } \\
\hline Female vs. male & & & & 0.03 & -0.89 to 0.94 & 0.00 & 0.96 \\
\hline Age & & & & 0.02 & -0.03 to 0.07 & 0.10 & 0.35 \\
\hline Education (yr) & & & & -0.18 & -0.32 to 0.08 & -0.12 & 0.24 \\
\hline Patients with ambulatory restriction vs. fully ambulatory & & & & 1.23 & -0.14 to 2.60 & 0.20 & 0.08 \\
\hline Secondary progressive vs. relapsing remitting & & & & -0.07 & -1.53 to 1.39 & -0.01 & 0.92 \\
\hline Primary-progressive vs. relapsing remitting & & & & 0.73 & -1.80 to 3.26 & 0.05 & 0.57 \\
\hline Disease duration & & & & -0.01 & -0.08 to 0.06 & -0.03 & 0.76 \\
\hline Annualized relapse rate & & & & -0.49 & -1.66 to 0.68 & -0.07 & 0.41 \\
\hline SDMT score & & & & -0.03 & -0.06 to 0.01 & -0.21 & $0.04^{*}$ \\
\hline
\end{tabular}

CI, confidence interval; SDMT, Symbol Digit Modality Test.

${ }^{\star} \mathrm{P}<0.05$, statistically significant difference.

$(\mathrm{r}=0.53, \mathrm{P}<0.001)$ and NRS for bowel function $(\mathrm{r}=-0.46, \mathrm{P}<$ $0.001)$.

In hierarchical regression models, after correction for physical disability, demographic features and disease course, the NRS for bowel function only was correlated with disease duration $(\beta=$ $-0.08 ; 95 \% \mathrm{CI},-0.14$ to $-0.02 ; \mathrm{P}=0.013)$. Both the total NBDS and ABSST total score were correlated with SDMT $(\beta=-0.10$; $95 \% \mathrm{CI},-0.18$ to $-0.02 ; \mathrm{P}<0.001$ and $\beta=-0.03 ; 95 \% \mathrm{CI},-0.06$ to $-0.01, \mathrm{P}=0.04$; respectively) (Table 3 , Fig. 2), after correction for physical disability, demographic features and disease course.

\section{DISCUSSION}

In this study, we showed that approximately $45 \%$ of MS patients experienced bowel/bladder symptoms throughout their disease course. Bowel/bladder dysfunction was associated with older age, progressive MS course, and higher physical disability. We also demonstrated independent associations of both bowel and bladder dysfunction with impaired cognition independently from the extent of physical disability and disease course.

The main finding of the present study is the interplay be- 

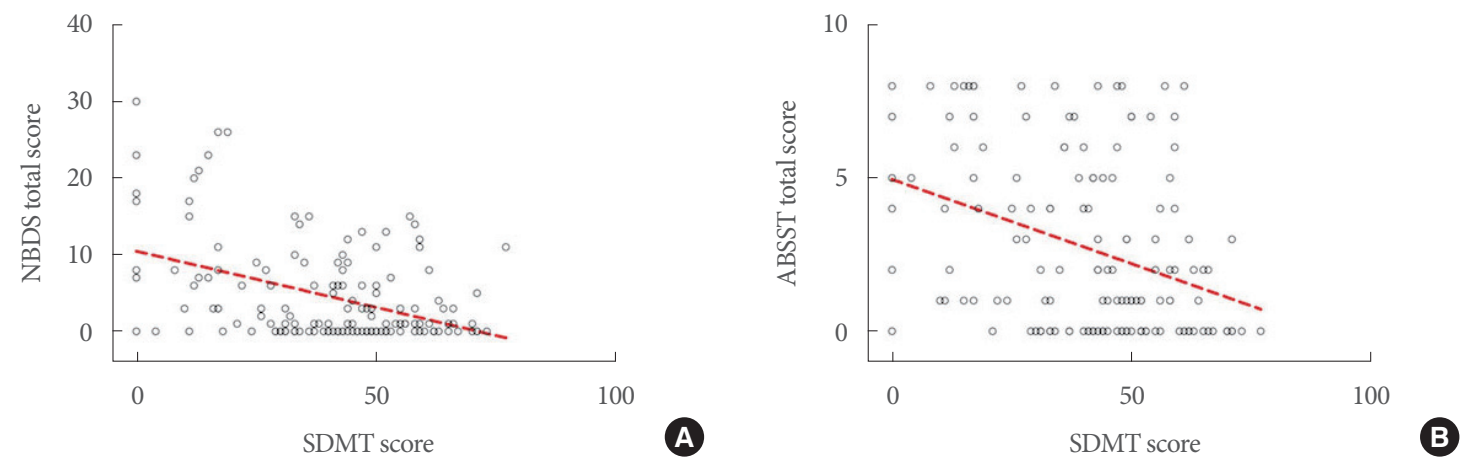

Fig. 2. Associations between bowel/bladder dysfunction and cognition. Scatter plots show the associations of the Symbol Digit Modality Test (SDMT) with both the total Neurogenic Bowel Dysfunction Score (NBDS) (A; $\beta=-0.10, \mathrm{P}<0.001)$ and Actionable Bladder Symptom Screening Tool (ABSST) total scores $(\mathrm{B} ; \beta=-0.03, \mathrm{P}=0.04)$.

tween cognition and bowel/bladder function in MS independently from physical disability. Cognitive impairment can affect up to $75 \%$ of MS patients $[13,14]$ and is associated with physical disability and limited mobility in MS [24], which can, in turn, affect bowel/bladder function. For example, patients with limited mobility may experience incontinence because they are not able to reach the bathroom on time. Therefore, in order to take into account physical disability when evaluating the association between cognition and bowel/bladder function, we evaluated the impact of cognition over and above physical disability and demographic features through a hierarchical regression model, thereby adjusting for these factors. The association between SDMT scores and bowel/bladder function still remained significant, with patients suffering from impaired cognition showing worse bowel/bladder control. From the neuropsychological point of view, Harvey et al. [25] described the influence of cognition on bladder voiding, elaborating upon the concept of "cognitive voiding." This concept describes how subjects aware of bladder filling integrate this information with other factors including a temporal map, voiding behavior, and habituation in order to decide when and where to void [25]. Specifically, attention and information processing speed are essential in integrating the awareness of bowel and bladder filling and the possibility/impossibility of voiding depending on the context. Strengthening the concept of cognitive voiding, it has been demonstrated that cognitive rehabilitation programs aimed at reinforcing dual task abilities and attention focus are also able to improve bowel/bladder function [26,27].

The association between cognition and bowel/bladder function may also rely on the common neurological pathways controlling both functions. As for attention and information pro- cessing explored through the SDMT, bowel/bladder function is associated with the structural integrity and functional activation of different structures throughout the central nervous system, namely, the frontal lobes, brainstem, cerebellum, thalamus, temporo-parietal lobes, and white matter bundles connecting the prefrontal cortex to subcortical structures [28-33]. However, magnetic resonance imaging studies exploring both bowel/ bladder and cognitive function are required in order to evaluate whether lesion location, resulting in disconnection between brain regions, or the neurodegeneration of selective cortical areas are relevant for both functions in MS patients. Such studies will not only provide information about the pathological anatomical substrates underpinning bowel/bladder dysfunction, but will also be useful for designing rehabilitation programs aimed at increasing activation in selected brain regions, perhaps through transcranial magnetic simulation.

Another noteworthy finding of the present study is the prevalence of bowel/bladder dysfunction in patients with MS, which we detected in about $45 \%$ of our MS sample. Specifically, 26 patients out of 150 (17.3\%) displayed bowel deficits and 60 out of 150 patients (40\%) presented with bladder deficits. Previous studies reported a prevalence from $50 \%$ to $95 \%$ for bladder deficits and a prevalence from $12 \%$ to $32 \%$ for bowel deficits $[7,34]$. Several factors account for wide prevalence range for both bladder and bowel dysfunction. Firstly, bowel/bladder dysfunction is very difficult to diagnose as patients may complain of various and heterogeneous symptoms due to an impaired storage or voiding process that may not be identified as directly related to MS unless a proper bowel/bladder assessment is performed. Thus, the absence of a multidisciplinary team in the clinical frame may lead to an underestimation of the prevalence of 
bowel/bladder dysfunction. Secondly, patients themselves do not associate bowel/bladder dysfunction with MS and often do not report the symptoms to clinicians. Patients may not seek help for their bowel/bladder symptoms as they are reluctant to talk about them to clinicians due to the social stigma surrounding the topic [6]. Lastly, there is no worldwide consensus on the screening tool that should be used to assess bowel/bladder function. Therefore, there is an urgent need to adopt a common screening tool in order to calculate the prevalence for bowel and bladder disorders in MS patients and to introduce these tools as outcomes in trials aimed at treating sphincter disturbances. However, a large Italian study reported that the prevalence of bladder deficits was $42 \%$ and that of bowel deficits was $11 \%$ [35]. This finding is in line with our data and confirms that our population is representative of the Italian population, thus reinforcing our findings on the correlation between cognition and bowel/bladder dysfunction. As a matter of fact, the tools we used in the present study, namely the NBDS and ABSST, are aimed at screening bowel/bladder deficits, but they are not able to disentangle these disorders (i.e., whether deficits are due to overactive bladder, urgency urinary incontinence, or sphincter dysfunction). Therefore, new studies aimed at assessing the relationship between cognition and specific bowel/bladder disorders would shed further light on the topic.

In conclusion, we demonstrated that bowel/bladder disorders are common in patients with MS and are associated with both physical and cognitive disability burdens. As their prevalence is quite high but patients are reluctant to report on sphincter symptoms, a self-administered screening questionnaire may facilitate the detection of these disorders. Moreover, as SDMT is becoming more and more embedded into the clinical assessment routine, a lower SDMT score should warrant clinicians investigating bowel/bladder dysfunction, due to the strong interplay between these 2 domains. Early identification of sphincter dysfunction in MS is helpful for clinicians to evaluate tailored treatment strategies. Finally, future imaging studies may evaluate common pathological substrates underlying cognitive and sphincter dysfunction in order to design tailored rehabilitation treatment stimulating the activation of selected cortical areas, perhaps through transcranial magnetic stimulation or through cognitive tasks reinforcing specific cognitive domains.

\section{AUTHOR CONTRIBUTION STATEMENT}

- Conceptualization: $A C, T C, F F, R L$
- Data curation: AC, TC, MM, FF, MP, BS, CVR, FS, RL, VBM

- Formal analysis: $A C, T C, M P, F S, R L$

- Methodology: AC, FF, $M P, C V R, F S, R L, V B M$

- Project administration: $A C, M P, B S$

- Visualization: M Moccia, FF, BS, CVR, FS

-Writing-original draft: $A C, T C, M M, R L, V B M$

-Writing-review \& editing: $A C, M M, F F, M P, B S, C V R, F S, R L$, $V B M$

\section{ORCID}

Carotenuto Antonio

0000-0002-1574-9693

Teresa Costabile

0000-0002-5997-0226

Marcello Moccia

0000-0003-2613-3090

Maria Petracca

0000-0001-9429-2769

Cinzia Valeria Russo

0000-0003-0345-8319

Francesco Saccà

0000-0002-1323-6317

Roberta Lanzillo

0000-0001-6388-8180

Vincenzo Brescia Morra

0000-0002-2807-6483

\section{REFERENCES}

1. Ochoa-Morales A, Hernandez-Mojica T, Paz-Rodriguez F, JaraPrado A, Trujillo-De Los Santos Z, Sanchez-Guzman MA, et al. Quality of life in patients with multiple sclerosis and its association with depressive symptoms and physical disability. Mult Scler Relat Disord 2019;36:101386.

2. Filippi M, Bar-Or A, Piehl F, Preziosa P, Solari A, Vukusic S, et al. Multiple sclerosis. Nat Rev Dis Primers 2018;4:43.

3. Litwiller SE, Frohman EM, Zimmern PE. Multiple sclerosis and the urologist. J Urol 1999;161:743-57.

4. Thiruppathy K, Preziosi G, Bajwa A, Sharma P, Cerdeira M, Ganesh S, et al. Multiple sclerosis related bowel dysfunction: pathophysiology, clinical manifestation and management. J Neurol Neurophysiol 2014;5:6.

5. Nortvedt MW, Riise T, Myhr KM, Landtblom AM, Bakke A, Nyland HI. Reduced quality of life among multiple sclerosis patients with sexual disturbance and bladder dysfunction. Mult Scler 2001; 7:231-5.

6. Koch T, Kralik D, Eastwood S, Schofield A. Breaking the silence: women living with multiple sclerosis and urinary incontinence. Int J Nurs Pract 2001;7:16-23.

7. Kalsi V, Fowler CJ. Therapy Insight: bladder dysfunction associated with multiple sclerosis. Nat Clin Pract Urol 2005;2:492-501.

8. Schumpf LF, Theill N, Scheiner DA, Fink D, Riese F, Betschart C. 
Urinary incontinence and its association with functional physical and cognitive health among female nursing home residents in Switzerland. BMC Geriatr 2017;17:17.

9. Haruta H, Sakakibara R, Ogata T, Panicker J, Fowler C), Tateno F, et al. Inhibitory control task is decreased in vascular incontinence patients. Clin Auton Res 2013;23:85-9.

10. Tkaczynska Z, Becker S, Maetzler W, Timmers M, Van Nueten L, Sulzer P, et al. Executive function is related to the urinary urgency in non-demented patients with Parkinson's disease. Front Aging Neurosci 2020;12:55.

11. Seseke S, Leitsmann C, Hijazi S, Trojan L, Dechent P. Functional MRI in patients with detrusor sphincter dyssynergia: is the neural circuit affected? Neurourol Urodyn 2019;38:2104-11.

12. Charil A, Zijdenbos AP, Taylor J, Boelman C, Worsley KJ, Evans AC, et al. Statistical mapping analysis of lesion location and neurological disability in multiple sclerosis: application to 452 patient data sets. Neuroimage 2003;19:532-44.

13. Chiaravalloti ND, DeLuca J. Cognitive impairment in multiple sclerosis. Lancet Neurol 2008;7:1139-51.

14. Rao SM, Leo GJ, Bernardin L, Unverzagt F. Cognitive dysfunction in multiple sclerosis. I. Frequency, patterns, and prediction. Neurology 1991;41:685-91.

15. Heesen C, Schulz KH, Fiehler J, Von der Mark U, Otte C, Jung R, et al. Correlates of cognitive dysfunction in multiple sclerosis. Brain Behav Immun 2010;24:1148-55.

16. Thompson AJ, Banwell BL, Barkhof F, Carroll WM, Coetzee T, Comi G, et al. Diagnosis of multiple sclerosis: 2017 revisions of the McDonald criteria. Lancet Neurol 2018;17:162-73.

17. Parmenter BA, Weinstock-Guttman B, Garg N, Munschauer F, Benedict RH. Screening for cognitive impairment in multiple sclerosis using the Symbol digit Modalities Test. Mult Scler 2007;13:527.

18. Van Schependom J, D’Hooghe MB, Cleynhens K, D'Hooge M, Haelewyck MC, De Keyser J, et al. The Symbol Digit Modalities Test as sentinel test for cognitive impairment in multiple sclerosis. Eur J Neurol 2014;21:1219-25,e71-2.

19. Krogh K, Christensen P, Sabroe S, Laurberg S. Neurogenic bowel dysfunction score. Spinal Cord 2006;44:625-31.

20. Preziosi G, Raptis DA, Raeburn A, Thiruppathy K, Panicker J, Emmanuel A. Gut dysfunction in patients with multiple sclerosis and the role of spinal cord involvement in the disease. Eur J Gastroenterol Hepatol 2013;25:1044-50.

21. McClurg D, Goodman K, Hagen S, Harris F, Treweek S, Emmanuel A, et al. Abdominal massage for neurogenic bowel dysfunction in people with multiple sclerosis (AMBER - Abdominal Massage for
Bowel Dysfunction Effectiveness Research): study protocol for a randomised controlled trial. Trials 2017;18:150.

22. Burks J, Chancellor M, Bates D, Denys P, Macdiarmid S, Nitti V, et al. Development and validation of the actionable bladder symptom screening tool for multiple sclerosis patients. Int J MS Care 2013; 15:182-92.

23. Jongen PJ, Blok BF, Heesakkers JP, Heerings M, Lemmens WA, Donders R. Simplified scoring of the Actionable 8-item screening questionnaire for neurogenic bladder overactivity in multiple sclerosis: a comparative analysis of test performance at different cut-off points. BMC Urol 2015;15:106.

24. Lynch SG, Parmenter BA, Denney DR. The association between cognitive impairment and physical disability in multiple sclerosis. Mult Scler 2005;11:469-76.

25. Harvey J, Finney S, Stewart L, Gillespie J. The relationship between cognition and sensation in determining when and where to void: the concept of cognitive voiding. BJU Int 2012;110:1756-61.

26. Villot A, Deffieux X, Billecocq S, Auclair L, Amarenco G, Thubert T. Influence of cognitive rehabilitation on pelvic floor muscle contraction: a randomized controlled trial. Neurourol Urodyn 2017;36: 1636-44.

27. Kushner DS, Johnson-Greene D. Changes in cognition and continence as predictors of rehabilitation outcomes in individuals with severe traumatic brain injury. J Rehabil Res Dev 2014;51:1057-68.

28. Arya NG, Weissbart SJ, Xu S, Rao H. Brain activation in response to bladder filling in healthy adults: an activation likelihood estimation meta-analysis of neuroimaging studies. Neurourol Urodyn 2017;36:960-5.

29. Rapps N, van Oudenhove L, Enck P, Aziz Q. Brain imaging of visceral functions in healthy volunteers and IBS patients. J Psychosom Res 2008;64:599-604.

30. Zorzon M, Zivadinov R, Locatelli L, Stival B, Nasuelli D, Bratina A, et al. Correlation of sexual dysfunction and brain magnetic resonance imaging in multiple sclerosis. Mult Scler 2003;9:108-10.

31. Griffiths D. Functional imaging of structures involved in neural control of the lower urinary tract. Handb Clin Neurol 2015;130: 121-33.

32. Grothe M, Domin M, Hoffeld K, Nagels G, Lotze M. Functional representation of the symbol digit modalities test in relapsing remitting multiple sclerosis. Mult Scler Relat Disord 2020;43:102159.

33. Forn C, Belenguer A, Belloch V, Sanjuan A, Parcet MA, Avila C. Anatomical and functional differences between the Paced Auditory Serial Addition Test and the Symbol Digit Modalities Test. J Clin Exp Neuropsychol 2011;33:42-50.

34. Nortvedt MW, Riise T, Frugard J, Mohn J, Bakke A, Skar AB, et al. 
IJ Carotenuto, et al. • Cognition and Sphincter Dysfunction in MS

Prevalence of bladder, bowel and sexual problems among multiple sclerosis patients two to five years after diagnosis. Mult Scler 2007; 13:106-12.

35. Alvino B, Arianna F, Assunta B, Antonio C, Emanuele D, Giorgia M, et al. Prevalence and predictors of bowel dysfunction in a large multiple sclerosis outpatient population: an Italian multicenter study. J Neurol 2021 Aug 4. https://doi.org/10.1007/s00415-02110737-w. [Epub]. 